\title{
ABA pretreatment can alter the distribution of polysomes in salt-stressed barley sprouts
}

Ewa Szypulska \& Stanisław Weidner

\begin{abstract}
ABA pretreatment can alter the distribution of polysomes in salt-stressed barley sprouts. - Acta Mus. Siles. Sci. Natur. 65: 257-261, 2016.

Abstract: The study analyzed caryopses of barley (Hordeum vulgare) cv. Stratus. Caryopses were germinated in darkness at $20^{\circ} \mathrm{C}$ in three experimental setups: (a) in distilled water for 24 hours, followed by $100 \mathrm{mM} \mathrm{NaCl}$ for another 24 hours (salinity stress, SS), (b) in $100 \mu \mathrm{M}$ of abscisic acid for the first 24 hours, followed by rinsing with distilled water to remove residual ABA, and in 100 $\mathrm{mM} \mathrm{NaCl}$ for another 24 hours (ABA pretreatment + salinity stress, ABAS), (c) in distilled water only (control, C). Changes in the content of free polysomes (FP), membrane-bound polysomes (MBP), cytoskeleton-bound polysomes (CBP) and cytomatrix-bound polysomes (CMBP) were examined in barley sprouts germinated in SS and ABAS treatments for 48 hours. In salt-stressed barley sprouts, the concentrations of membrane-bound and cytoskeleton-bound polysomes (MBP, CBP and CMBP) decreased significantly, whereas an increase was noted only in the free polysome (FP) fraction. ABA pretreatment altered the distribution of polysomes in stressed plants. The content of cytoskeletonbound polysomes (CBP and CMBP) increased, FP levels decreased, whereas no changes in MBP content were observed in response to ABA treatment. Our results suggest that plants respond to salt stress by increasing the concentrations of free polysomes that are probably released from damaged cell structures, mainly membranes. Our present and previous findings indicate that ABA could inhibit the release of FP in stressed plants by enhancing polysome binding to the cytoskeleton.
\end{abstract}

Key words: abscisic acid, salinity stress, polysomes, barley sprouts

\section{Introduction}

Salinity considerably limits the productivity of glycophytes, which are the majority of agricultural products. Salinity stress exerts adverse effects on germination, and it compromises the growth, development and survival of plants. Unlike halophytes, which are salt-tolerant plants, crops such as rice, wheat and barley are salt-sensitive species (glycophytes). Barley is more salt tolerant than rice and wheat (Munns \& Tester 2008). Salinization results mainly from human activities such as irrigation due to the use of brackish water. More than 45 million hectares of irrigated land worldwide (about $20 \%$ of global land area) has been damaged by salt, and 1.5 million hectares of land is taken out of production each year due to high soil salinity (Munns \& Tester 2008; Gupta \& Huang 2014). Salinity stress exerts harmful effects on plants, including osmotic stress, ionic toxicity, oxidative stress and generation of reactive oxygen species (ROS). Increased production of ROS causes damage to proteins, lipids, RNA and DNA (Ahmad et al. 2012). Salinity stress induces various physiological changes, such as cell membrane injury, nutrient imbalance, enzymatic inhibition and photosynthetic dysfunction (Rahman et al. 2016). At the molecular level, plants respond to salinity by increasing the production and accumulation of ABA in tissues (Xiong et al. 2002; Sah et al. 2016). ABA inhibits plant growth and development, and this plant stress hormone modulates the expression of salt and water deficit-responsive genes (Wani et al. 2016). ABA can also regulate gene expression, both at transcriptional and translational level (Bray 2002). Salinity stress generally decreases translational activity in stressed plants. One of the earliest salt-induced metabolic changes involves the breakdown of polysomes to monosomes (first hour of exposure to salt stress), followed by decreased protein synthesis and 
the accumulation of free amino acids (such as proline), (Melamed et al. 2008). Polysomes are a dynamic component of the translational machinery in plant cells. They come in several forms, including free polysomes (FP), membrane-bound polysomes (MBP) and cytoskeletonbound polysomes (CBP). Some authors provided evidence for the existence of a fourth form of polysomes in plant cells, namely cytoskeleton-membrane-bound polysomes (cytomatrixbound polysomes, CMBP) (Davies \& Abe 1995; Abe et al. 2003). Little is known about the effect of salinity on the formation of different polysomes. The aims of this study were: (1) to examine the influence of salt stress on changes in the distribution of different polysome fractions (FP, MBP, CBP, CMBP), and (2) to evaluate changes in the responses of saltstressed plants pretreated with ABA.

\section{Materials and Methods}

\section{Plant material and germination conditions}

The experiment was conducted on barley (Hordeum vulgare) caryopses cv. Stratus supplied by the Plant Cultivation Station in Strzelce. Seeds were surface disinfected in 0.5\% sodium hypochlorite for 20 minutes and washed with sterilized water. Twenty intact grains were placed on two layers of grade 1 Whatman paper (Whatman, Midstone, Kent, UK) in a Petri dish $\left(\varnothing 9 \mathrm{~cm}\right.$ ) and were germinated in darkness at $20^{\circ} \mathrm{C}$ under various conditions. Caryopses were germinated in distilled water for 24 hours, followed by $100 \mathrm{mM} \mathrm{NaCl}$ for another 24 hours (salinity stress, SS) - Fig 1 . Seeds were also incubated in $100 \mu \mathrm{M}$ of abscisic acid for the first 24 hours, then rinsed with distilled water to remove residual $\mathrm{ABA}$, and subjected to $100 \mathrm{mM} \mathrm{NaCl}$ for another 24 hours (ABA pretreatment + salinity stress, ABAS). Seeds germinated in distilled water only were the control (C). Dry weight was determined by drying $200 \mathrm{mg}$ of fresh embryos/germs in an oven at $105^{\circ} \mathrm{C}$ for 24 hours.

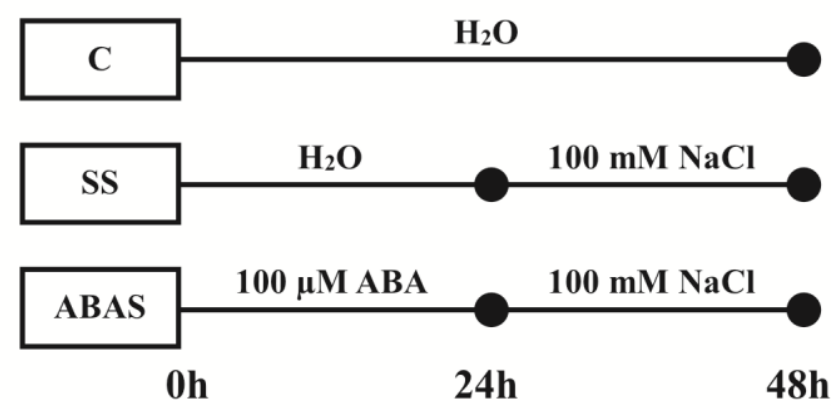

Fig 1: Seed germination conditions

\section{Polysome isolation and quantification}

Cytoskeleton-stabilizing buffer $\mathrm{C}$ (Abe and Davies 1991) containing 5mM HEPES, $10 \mathrm{mM} \mathrm{Mg}(\mathrm{OAc})_{2}$, $2 \mathrm{mM}$ EGTA and 1mM PMSF adjusted to $\mathrm{pH} 7.5$ with $9.8 \mathrm{mM}$ of $\mathrm{KOH}$ was used for the isolation of cytoskeleton fractions from barley caryopses after $48 \mathrm{~h}$ of germination. The buffer supports sequential isolation of four polysome fractions (Davies \& Abe 1995): free polysomes (FP), membrane-bound polysomes (MBP), cytoskeleton-bound polysomes (CBP) and cytoskeleton-membrane-bound polysomes (CMBP). All fractions were layered on a $0.5 \mathrm{ml}$ pad of $50 \%(\mathrm{w} / \mathrm{v})$ sucrose in buffer B $(50 \mathrm{mM}$ Tris-HCl, pH 7.5; 20mM KOAc, $10 \mathrm{mM}$ $\left.\mathrm{Mg}(\mathrm{OAc})_{2}\right)$ and were centrifuged for $1.5 \mathrm{~h}$ at 300,000g in the Beckman SW 55Ti rotor. Polysomal pellets were rinsed in water and resuspended in $350 \mu \mathrm{l}$ of $0.5 \%$ PTE. Resuspended polysomes were centrifuged at top speed (approximately 18,000g) for $2 \mathrm{~min}$ in a microfuge, and $0.2 \mathrm{ml}$ aliquots were layered on $15 \%$ to $60 \%$ (w/v) linear sucrose gradients in buffer B and centrifuged at 300,000g in the Beckman SW 55Ti rotor for 45 min. The gradients were scanned at $254 \mathrm{~nm}$ on a UA-5 flow recorder (ISCO, Lincoln, NE, USA) to display subunits, monosomes and polysomes. All operations were conducted at $0-4^{\circ} \mathrm{C}$. The applied methods were described in detail in an earlier paper (Weidner et al. 2003). Polysome levels were determined by measuring the area under the polysome profile after subtracting the gradient baseline OD (absorbance of the gradient loaded with $1 \mathrm{ml}$ of the extraction buffer). Ribosomes were quantified on the assumption that the absorbance of $1 \%$ ribosome solution (measured in a cuvette with $1 \mathrm{~cm}$ optical path at $260 \mathrm{~nm}$ ) equals 13.5 (Gualerzi \& Cammarano 1969). 


\section{Results}

The ribosome content of every analyzed polysome fraction $(\mathrm{mg} / \mathrm{g} \mathrm{DW})$ was calculated according to the method proposed by Gualerzi and Cammarano. The FP, MBP, CBP and CMBP profiles were used to determine the percentage of effective polysomes in each fraction (Fig. 2), and the actual content of FP, MBP, CBP and CMBP polysomes (mg/g DW) was calculated in the tested tissues (Fig. 3). The values of FP, MBP, CBP and CMBP were compared between SS and control treatments, and ABAS and SS treatments. The observed changes between the compared samples were analyzed statistically in Duncan's parametric test, and the results were regarded as statistically significant at $\mathrm{p} \leq 0.05$.

A profile sedimentation analysis revealed downregulation of polysome formation under stress conditions (Fig. 2). The formation of MBP was strongly inhibited, and a decrease in $\mathrm{CBP}$ and CMBP levels was also noted. The concentrations of free monosomes and ribosomal subunits increased in SS treatment, which led to a decrease in free polysome content. ABA pretreatment increased $\mathrm{CBP}$ and CMBP levels, which were even higher than in the control treatment. A decrease in FP content and no changes in MBP levels were observed in ABAS treatment (Fig. 2).

An analysis of the total content of polysomes in each fraction (FP, MBP, CBP and CMBP) from different treatments revealed (1) a significant increase in FP content and a decrease in MBP, CBP and CMBP levels in SS treatment; and (2) an increase in CBP and CMBP content and a decrease in FP levels in ABAS treatment (Fig. 3).

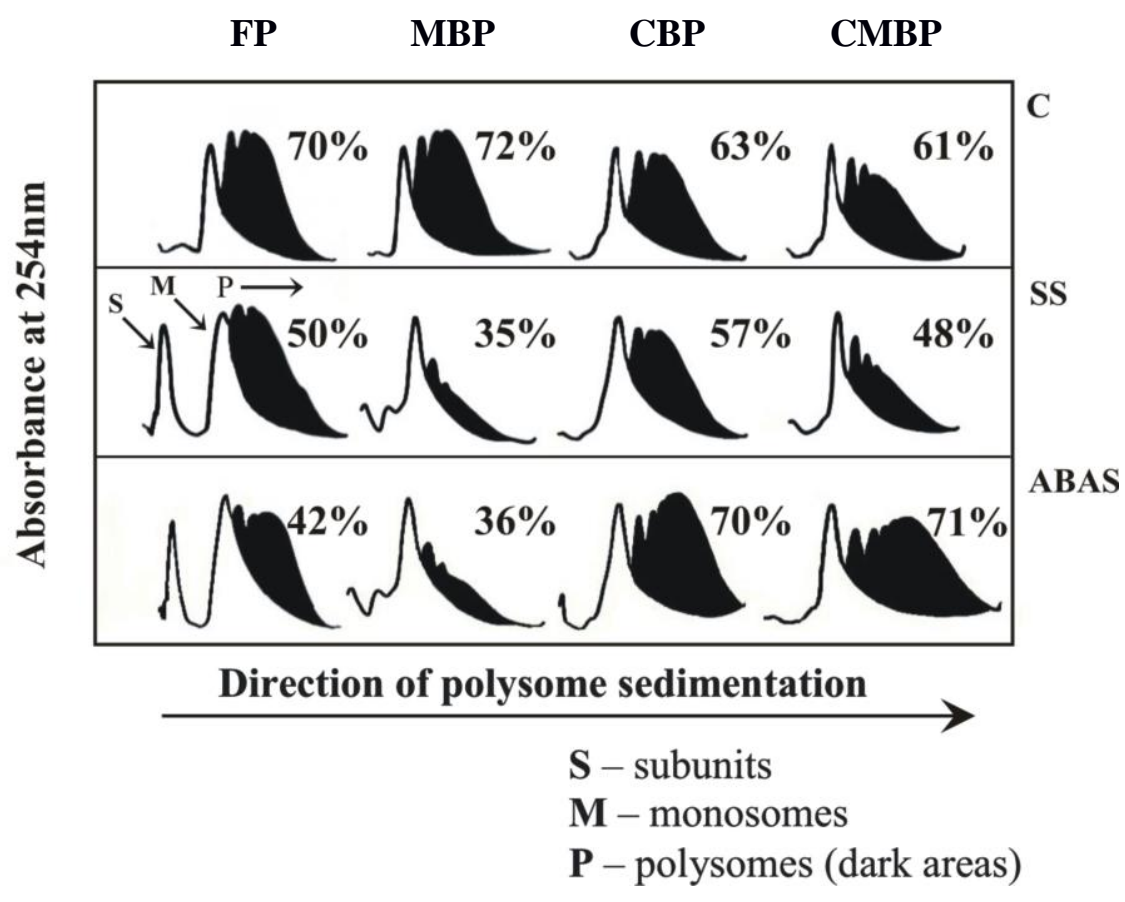

Fig 2: The effects of salinity stress and ABA pretreatment on the sub-cellular distribution of polyso-mes: individual profiles. The percentage of polysomes in each fraction (FP, MBP, CBP, CMBP) is indicated above the dark areas 


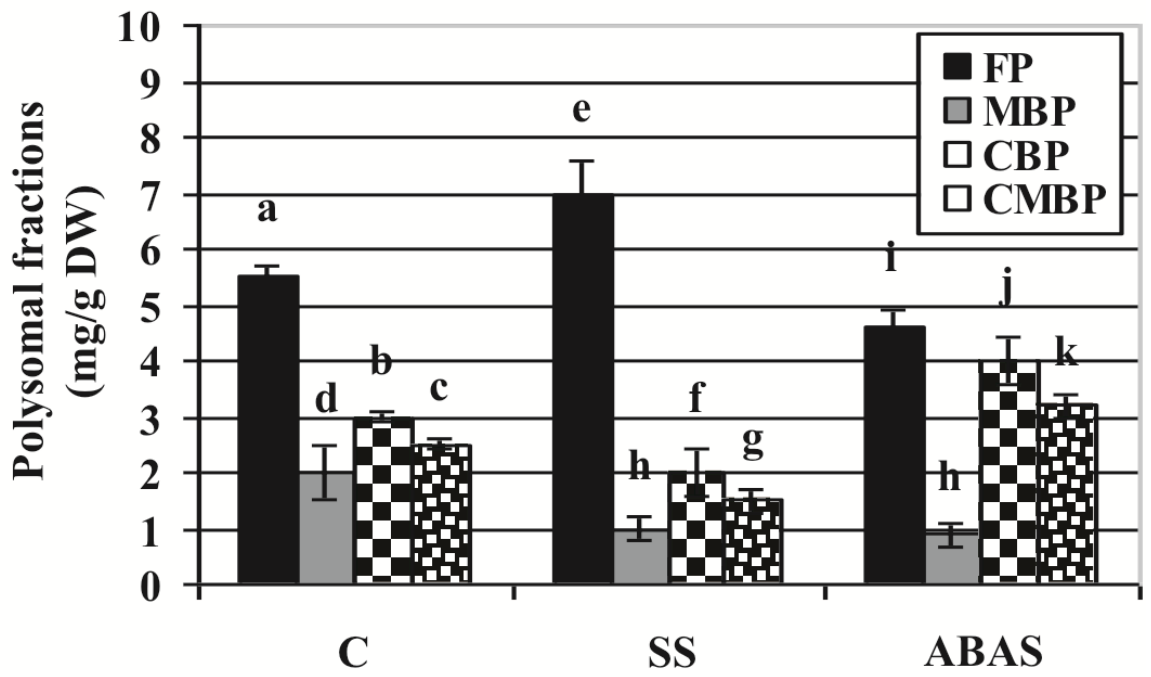

Fig 3: The effects of salinity stress and ABA pretreatment on the sub-cellular distribution of polysomes: detailed analysis. Statistically significant changes at $\mathrm{p} \leq 0.05$ are denoted by different letters

\section{Discussion}

Plants exposed to salinity stress exhibit characteristic cellular and metabolic responses. One of these responses is the upregulation of stress-related genes (Seki et al. 2002; Munns 2005; Zheng 2012), and the upregulation or downregulation of the synthesis of selected proteins (Witzel 2009). Abscisic acid (ABA) is a crucial hormone for plant growth and development. ABA also plays an important role in integrating various stress signals and controlling downstream stress responses (Tuteja 2007). The gene expression process involves several regulatory steps, from transcription to post-transcription, translation and posttranslation. Our study focused on the regulation of translational processes at the polysome distribution level in salt-stressed and ABA-pretreated sprouts.

Our results suggest that plants respond to salt stress by increasing the concentrations of free polysomes, monosomes and ribosomal subunits that are probably released from damaged cell structures, mainly membranes. However, the high percentage of cytoskeleton-bound polysomes in the CBP fraction could indicate that this fraction plays the key role in protein synthesis during salinity stress.

Our present and previous findings indicate that ABA could inhibit the release of FB in stressed plants by enhancing polysome binding to the cytoskeleton. In our previous study, ABA pretreatment increased the content of cytomatrix-bound polysomes, which are strongly bound to both the membrane and the cytoskeleton (Szypulska \& Weidner 2011). We also found that exogenous abscisic acid improves the stability of polysomes, possibly due to the high content of bound cytoskeletal structures (Weidner et al. 2006). Our results suggest that ABA could contribute to higher salt tolerance by regulating polysome distribution and stability in plant cells, in particular by increasing the content of cytoskeleton-bound fractions.

\footnotetext{
Abbreviations

ABA - abscisic acid, CBP - cytoskeleton-bound polysomes, CMBP - cytoskeleton-membrane-bound polysomes (cytomatrix-bound polysomes), EGTA - ethylene glycol-bis( $\beta$-aminoethyl ether)-N,N,N',N'tetraacetic acid, FP - free polysomes, HEPES - N-2-hydroxyethylpiperazine-N'2'ethanesulfonic acid, KOAcpotassium acetate, Luc - luciferase, $\mathrm{MBP}$ - membrane-bound polysomes, $\mathrm{Mg}(\mathrm{OAc})_{2}$ - magnesium acetate, PMSF - phenylmethyl-sulfonyl fluoride, PTE - polyoxyethylene-10-tridecyl ether, Tris - tris-(hydroxymethyl)aminomethane.
} 


\section{References}

Abe S., Azama K., Sugimoto H. \& Davies E. (2003): Protein accumulation in the maize endosperm: role of polyribosomes and the cytoskeleton. - Plant Physiol Biochem 41: 125-131.

Abe S. \& Davies E. (1991): Isolation of F-actin from pea stems: Evidence from fluorescence microscopy. Protoplasma 163: 51-61.

Ahmad P., Hakeem K.R., Kumar A., Ashraf M. \& Akram N.A. (2012): Salt-induced changes in photosynthetic activity and oxidative defense system of three cultivars of mustard (Brassica juncea L.). - Afr J Biotechnol 11: 2694-2703.

Bray E.A. (2002): Abscisic acid regulation of gene expression during water-deficit stress in the era of the Arabidopsis genome. - Plant Cell and Environment 25: 153-161.

Davies E. \& Abe S. (1995): Method for isolation and analysis of polyribosomes. - Methods Cell Biol 50: 209222.

Gualerzi C. \& Cammarano P. (1969): Comparative electrophoretic studies on the protein of chloroplast and cytoplasmic ribosomes of spinach leaves. - Biochim Biophys Acta 190: 170-186.

Gupta B. \& Huang B. (2014): Mechanisms of salinity tolerance in plants: physiological, biochemical, and molecular characterization. - Inter J of Genomics 14: 1-18.

Melamed D., Pnueli L. \& Arava Y. (2008): Yeast translational response to high salinity: global analysis reveals regulation at multiple levels. - RNA 14: 1337-1351.

Munns R. (2005): Genes and salt tolerance: bringing them together. - New Phytol 167: 645-663.

Munns R. \& Tester M. (2008): Mechanisms of salinity tolerance. - Annu. Rev Plant Biol 59: 651-81.

Rahman A., Nahar K., Hasanuzzaman M. \& Fujita M. (2016): Calcium supplementation improves $\mathrm{Na}^{+} / \mathrm{K}^{+}$ratio, antioxidant defense and glyoxalase systems in salt-stressed rice seedlings. - Front Plant Sci. 7: 609.

Sah S.K., Reddy K.R. \& Li J. (2016): Abscisic Acid and Abiotic Stress Tolerance in Crop Plants. - Front Plant Sci. 7: 571.

Seki M., Narusaka M., Ishida J., Nanjo T., Fujita M., Oono Y., Kamiya A., Nakajima M., Enju A., Sakurai T., Satou M., Akiyama K., Taji T., Yamaguchi-Shinozaki K., Carninci P., Kawai J., Hayashizaki Y. \& Shinozaki K. (2002): Monitoring the expression profiles of 7000 Arabidopsis genes under drought, cold and high-salinity stresses using a full-length cDNA microarray. - Plant J 31: 279-292.

Szypulska E. \& Weidner S. (2011): Importance of cytomatrix-bound polysomes to synthesis of lysinecontaining proteins in triticale germs under ABA treatment. - Acta Physiol Plant 33: 1461-1465.

Tuteja N. (2007): Abscisic Acid and Abiotic Stress Signaling. - Plant Sign Beh 2: 135-138.

Wani S.H., Kumar V., Shriram V. \& Sah S.K. (2016): Phytohormones and their metabolic engineering for abiotic stress tolerance in crop plants. - The crop J 4: 162-176.

Weidner S., Frączek E., Romanowska M., Amarowicz R., Abe S. \& Davies E. (2003): The influence of abscisic acid on different polysomal populations in embryonal tissue during pea seeds germination. - Acta Physiol Plant 25: 5-12.

Weidner S., Każarnowicz M., Frączek E., Amarowicz R. \& Karamać M. (2006): Exogenous abscisic acid increases stability of polysomes in embryos of triticale caryopses during germination. - Acta Physiol Plant 28: 627-634.

Witzel K., Weidner A., Surabhi G.K., Borner A. \& Mock H.P. (2009): Salt stress-induced alterations in the root proteome of barley genotypes with contrasting response towards salinity. - J of Exp Bot 60: 35453557.

Xiong L., Schumaker K.S. \& Zhu J.K. (2002): Cell signaling during cold, drought, and salt stress. - The Plant Cell S165-S183.

Zheng L., Liu G., Meng X., Liu Y., Ji X., Li Y., Nie X. \& Wang Y. (2013): A WRKY gene from Tamarix hispida, ThWRKY4, mediates abiotic stress responses by modulating reactive oxygen species and expression of stress-responsive genes. - Plant Mol Biol 82: 303-320.

Authors' addresses: Ewa Szypulska \& Stanisław Weidner, Department of Biochemistry, Faculty of Biology, University of Warmia and Mazury in Olsztyn, Oczapowskiego 1A, 10-957 Olsztyn-Kortowo, Poland.

E-mail: ewa.fraczek@uwm.edu.pl. 